\title{
THE EROS DATA
}

GENTER
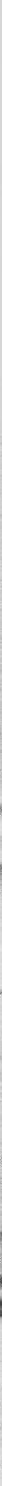

15x+ $6=3=0$
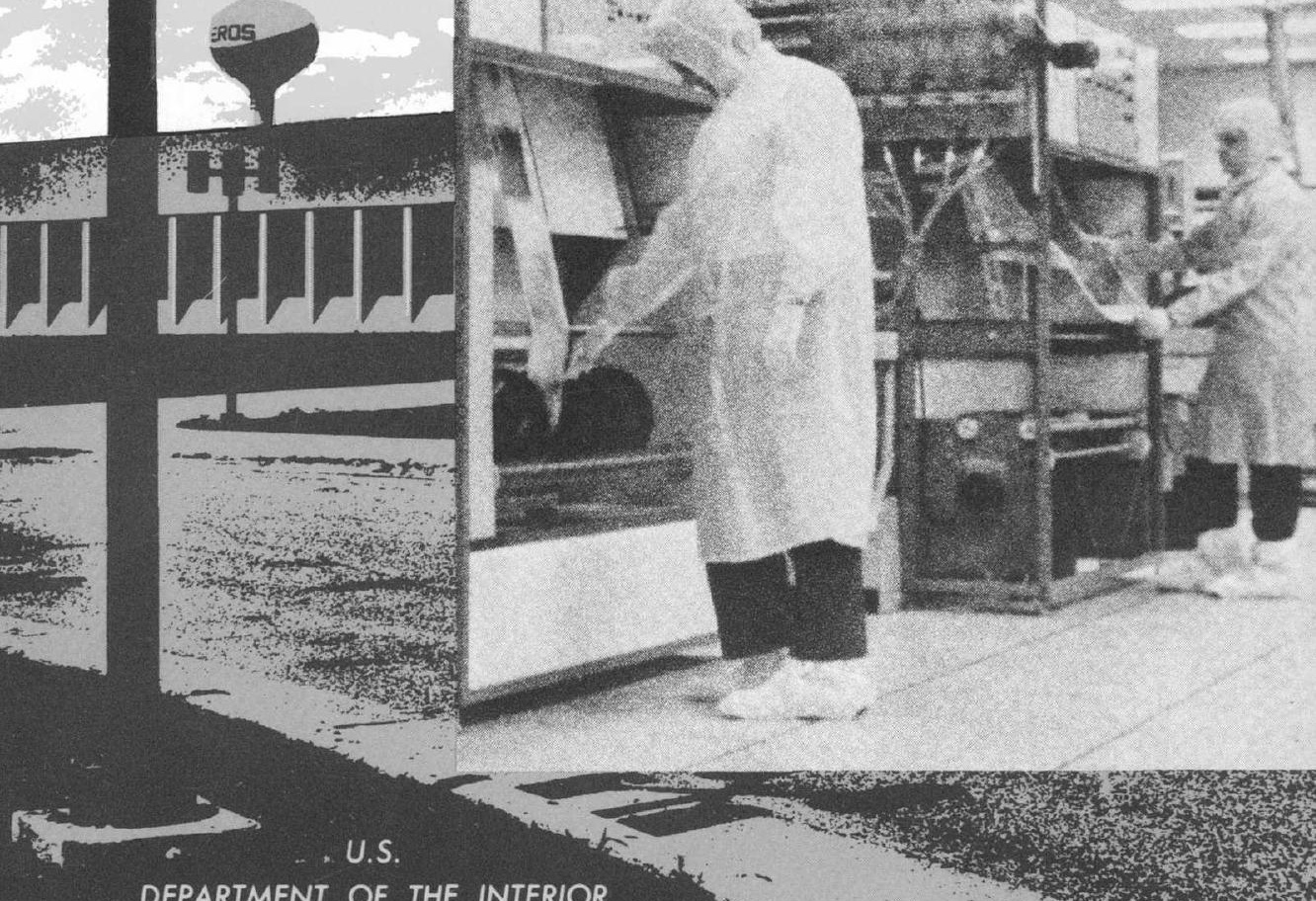

, U.S.

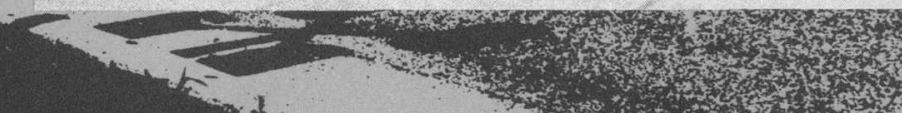

GEOLOGICAL SURVEY 


\section{FOR INFORMATION ON}

EROS and the EROS Data Center-see page 2

Data and products available-see page 7

How to inquire about available data of your area of interest-see page 14

How to understand computer listing-see page 16

To place an order-see page 18

An easy method for ordering satellite imagery of the United States-see page 20

To obtain custom service and priority handling-see page 23

If you live in another country and wish to order imagery or photography - see page 24

To obtain assistance in the use of data-see page 26

Visiting the EROS Data Center-see page 27

\section{NOTE TO NONTECHNICAL USERS:}

1. A complete understanding of the technical descriptions and terms used in this publication is not necessary when ordering photography or imagery for nontechnical purposes. The procedure entails: reviewing descriptions to determine type of photography or imagery desired; sending the inquiry form to determine availability; and placing an order. The staff at the EROS Data Center will assist you with your order.

2. In January 1975, the name of the Earth Resources Technology Satellite (ERTS) was changed to LANDSAT. 


\section{THE EROS PROGRAM}

The Earth Resources Observation Systems (EROS) Program of the U.S. Department of the Interior, administered by the Geological Survey, was created in 1966 to apply remote-sensing techniques to the inventory, monitoring, and management of resources. To meet its primary objective, the EROS Program includes research and training in the interpretation and application of remotely sensed data and provides remotely sensed data at nominal cost to scientists, resource planners, managers, and the public.

\section{THE EROS DATA CENTER}

The EROS Data Center, 16 miles $(25 \mathrm{~km})$ northeast of Sioux Falls, South Dakota, is operated by the EROS Program to provide access to NASA's LANDSAT [formerly Earth Resources Technology Satellite (ERTS)] imagery, aerial photography acquired by the U.S. Department of the Interior, and photography and imagery acquired by the National Aeronautics and Space Administration (NASA) from research aircraft and from Skylab, Apollo, and Gemini spacecraft. The primary functions of the Center are data storage and reproduction, and user assistance and training.

This publication describes the Data Center operations, data products, services, and procedures for ordering remotely sensed data. The EROS Data Center and its principal facility, the 120,000-square-foot

Sioux Falls can be reached conveniently by interstate and connecting highway networks.

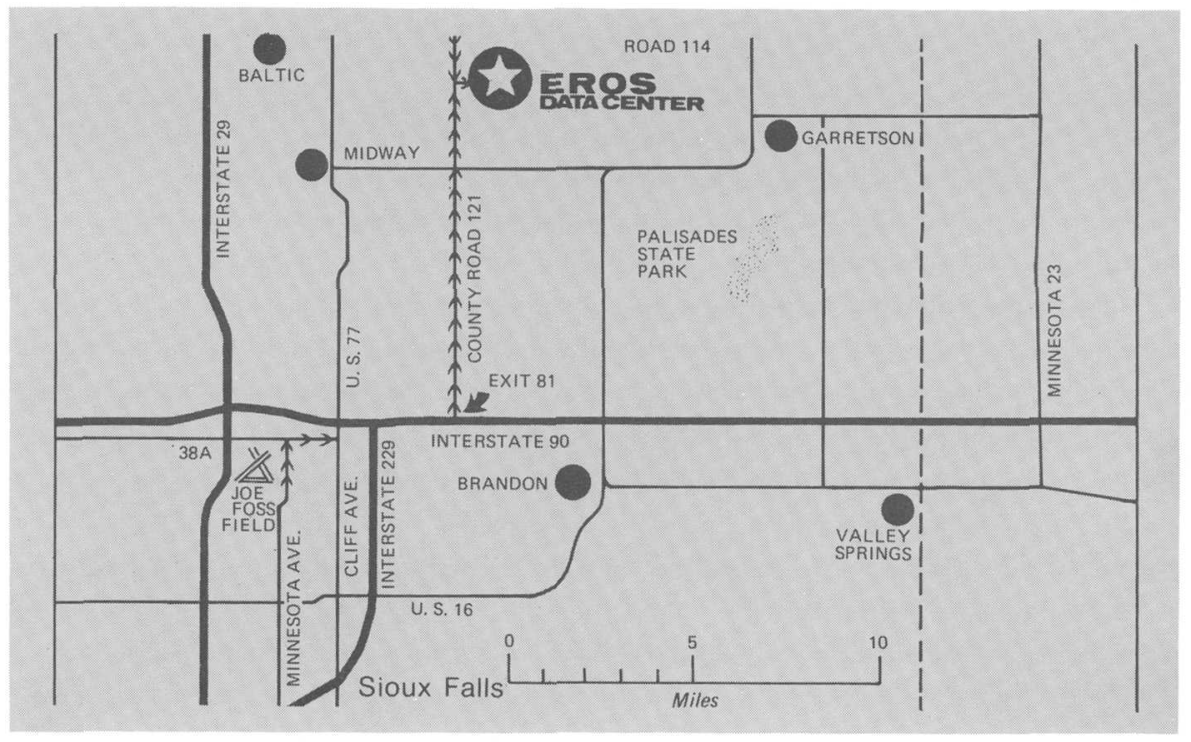




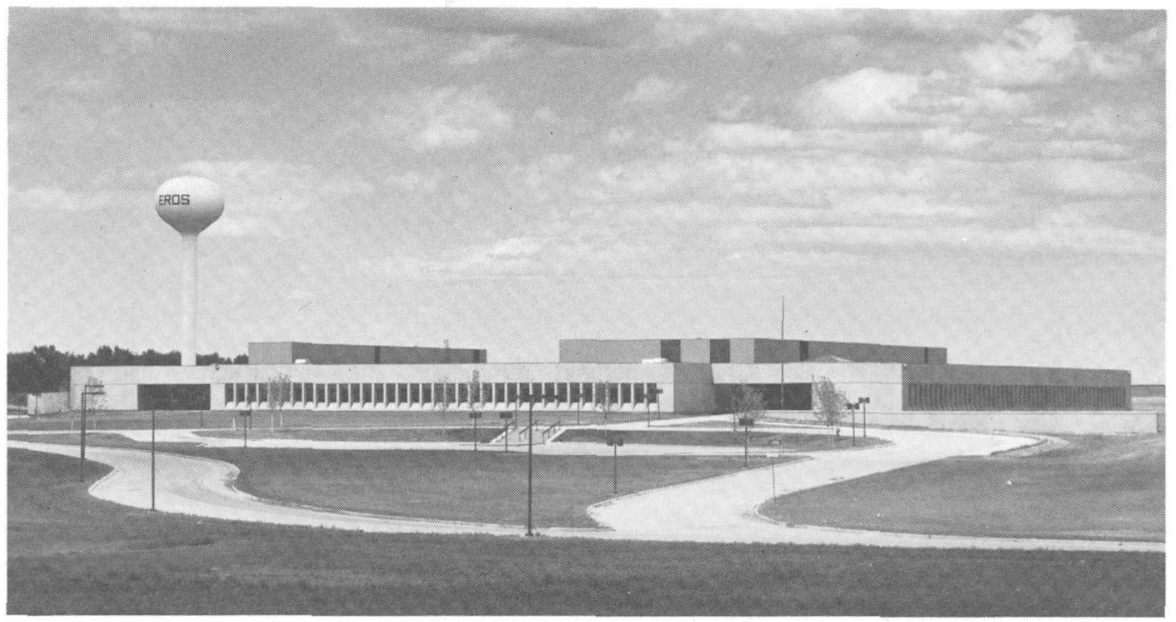

The principal facility at the Data Center is the 120,000 square-foot $\left(11,200-\mathrm{m}^{2}\right)$ Karl E. Mundt Federal Building.

$\left(11,200 \mathrm{~m}^{2}\right)$ Karl E. Mundt Federal Building, were dedicated August 7, 1973.

At the heart of the Data Center is a central computer complex which controls a data base of over 5 million images and photographs of the Earth's surface features, performs searches of specific geographic areas of interest, and serves as a management tool for the entire data reproduction process. The computerized data storage and retrieval system is based on a geographic system of latitude and longitude, supplemented

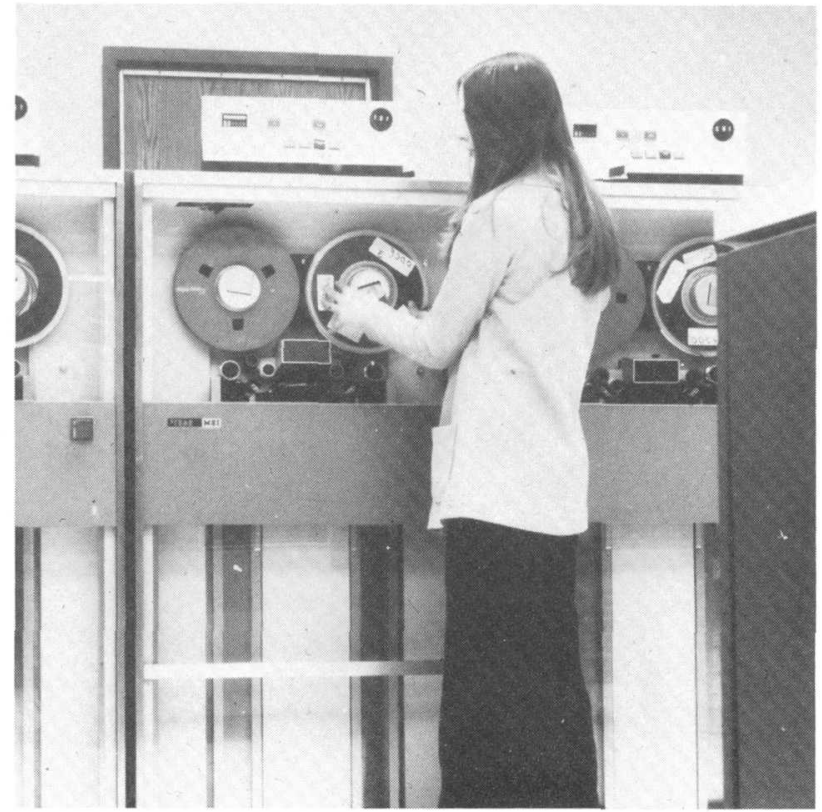

The computer provides immediate access to and geographic retrieval of the 5 million frames of imagery and photography. 
by information about image quality, cloud cover, and type of data. A customer's inquiry about availability of remotely sensed data may be about a geographic point location or a rectangular area specified by latitude and longitude corner coordinates. Depending on customer requirements, a computer geographic search will print out a listing of available imagery and photography from which the requestor can make a final selection. Receipt of a prepaid order initiates processing. To place an order, to inquire about the availability of data, or to establish a standing order, please contact:

\section{User Services Unit \\ EROS Data Center}

Sioux Falls, South Dakota 57198

Phone: 605-594-6511, extension 151

FTS: $\quad 605-594-6151$

Guidance in the use of remotely sensed data is available at the EROS Data Center in the form of scheduled training courses and workshops. The scientific teaching staff at the Center periodically offers discipline-oriented courses in subjects such as agriculture, forestry, geography, geology, and hydrology. Visitors to the Data Center will also get assistance in the operation of specialized equipment such as densitometers, additive color viewers, zoom transfer scopes, and stereo viewers, and in the use of computerized multispectral systems to classify specific phenomena.

Assistance is provided in applications of remotely sensed data to agriculture, forestry, geology, hydrology, and other studies of the environment and natural resources.

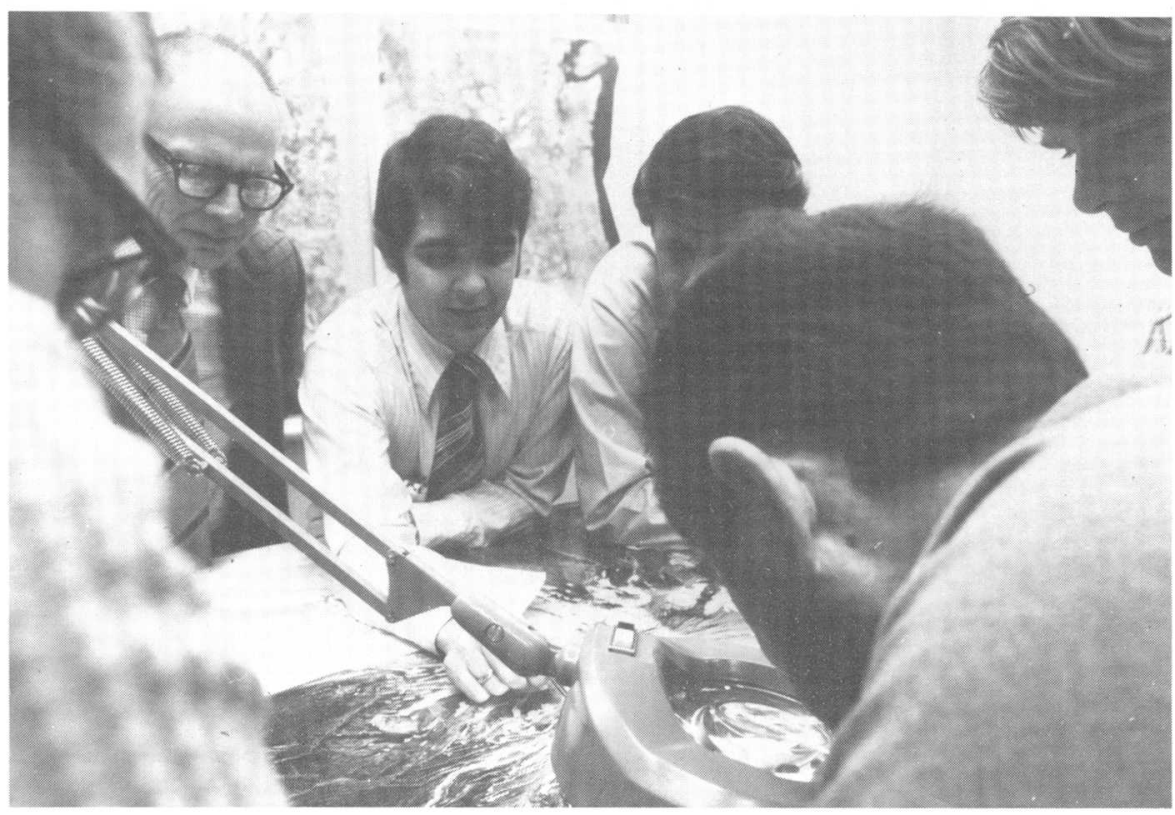




\section{EROS APPLICATIONS ASSISTANCE FACILITIES}

The EROS Data Center also operates several Applications Assistance Facilities which maintain microfilm copies of data archived at the Center and provide computer terminal inquiry and order capability to the central computer complex at the EROS Data Center. Scientific personnel are available for assistance in applying the data to a variety of resource and environmental problems and for assistance in ordering data from the Data Center.

It is recommended that Applications Assistance Facilities be contacted by phone or mail in advance, so that suitable arrangements can be made for a visit.

$\begin{array}{ll}\text { EROS Applications Assistance } & \text { EROS Applications Assistance } \\ \text { Facility } & \text { Facility } \\ \text { U.S. Geological Survey } & \text { HQ Inter American Geodetic Survey } \\ \text { Room 202, Building 3 } & \text { Headquarters Building } \\ \text { 345 Middlefield Road } & \text { Drawer 934 } \\ \text { Menlo Park, California 94025 } & \text { Fort Clayton, Canal Zone } \\ \text { Phone: 415-323-2727 } & \text { Phone: 83-3897 } \\ \text { Hours: 8:00-4:15 } & \text { Hours: 7:00-3:45 } \\ \text { EROS Applications Assistance } & \text { EROS Applications Assistance } \\ \text { Facility } & \text { Facility } \\ \text { EROS Data Center } & \text { U.S. Geological Survey } \\ \text { U.S. Geological Survey } & \text { Room 2404B, Building 25 } \\ \text { Sioux Falls, South Dakota 57198 } & \text { Federal Center } \\ \text { Phone: 605-594-6511 } & \text { Denver, Colorado 80225 } \\ \text { Hours: 8:00-4:30 } & \text { Phone: 303-234-4879 } \\ \text { EROS Applications Assistance } & \text { Hours: 8:00-4:30 } \\ \text { Facility } & \text { EROS Applications Assistance } \\ \text { U.S. Geological Survey } & \text { Facility } \\ \text { Room 8-210, Building 1100 } & \text { U.S. Geological Survey } \\ \text { National Space Technology } & \text { Room 5017, Federal Building } \\ \text { Laboratories } & \text { 230 North First Avenue } \\ \text { Bay St. Louis, Mississippi 39520 } & \text { Phoenix, Arizona 85025 } \\ \text { Phone: 601-688-3472 } & \text { Phone: 602-261-3188 } \\ \text { Hours: 8:00-4:30 } & \text { Hours: 8:00-5:00 } \\ \text { EROS Applications Assistance } & \text { EROS Applications Assistance } \\ \text { Facility } & \text { Facility } \\ \text { University of Alaska } & \text { U.S. Geological Survey } \\ \text { Geophysical Institute } & 1925 \text { Newton Square East } \\ \text { College, Alaska } 99701 \text { (Fairbanks) } & \text { Reston, Virginia 22090 } \\ \text { Phone: } 907-479-7558 & \text { Phone: 703-860-7868 } \\ \text { Hours: 8:00-5:00 } & \text { Hours: 8:00-4:15 } \\ & \end{array}$




\section{EROS DATA REFERENCE FILES}

EROS Data Reference Files have been established throughout the United States to maintain microfilm copies of the data available from the Data Center and to provide guides to assist the visitor in reviewing and ordering data. This allows the visitor to view microfilm copies of the data before placing an order. Applications assistance by scientists is not provided at EROS Data Reference Files. The table below lists the address, telephone number, and hours of operation of each of the eleven Data Reference Fites.

EROS Data Reference File

Public Inquiries Office

U.S. Geological Survey

108 Skyline Building

508 Second Avenue

Anchorage, Alaska 99501

Phone: 907-277-0577

Hours: 9:00-5:30

EROS Data Reference File

Public Inquiries Office

U.S. Geological Survey

Room 7638, Federal Building 300 North Los Angeles Street Los Angeles, California 90012

Phone: 213.688-2850

Hours: 9:30-4:00

EROS Data Reference File

State Topographic Office

Lafayette Building, Koger Office

Center

Tallahassee, Florida 32304

Phone: 904-488-2168

Hours: 8:15-5:15

EROS Data Reference File

University of Hawaii

Department of Geography

Room 313C, Physical Science

Building

Honolulu, Hawaii 96825

Phone: 808-944-8463

Hours: $8: 00-4: 00$
EROS Data Reference File

Topographic Office

U.S. Geological Survey

900 Pine Street

Rolla, Missouri 65401

Phone: 314-364-3680

Hours: $8: 00-5: 00$

EROS Data Reference File

Water Resources Division

U.S. Geological Survey

975 West Third Avenue

Columbus, Ohio 43212

Phone: 614-469-5553

Hours: $8: 00-4: 30$

EROS Data Reference File Water Resources Division U.S. Geological Survey

Room 343, Post Office and Court

House Building

Albany, New York 12201

Phone: 518.474 .3107 or 6042

Hours: $8: 00-4: 30$

EROS Data Reference File

Bureau of Land Management

729 NE. Oregon Street

Portland, Oregon 97208

Phone: 503-234-3361, ext. 4000

Hours: $8: 00-4: 00$ 
EROS Data Reference File

U.S. Geological Survey

5th Floor

80 Broad Street

Boston, Massachusetts 02110

Phone: 617.223.7202

Hours: 9:00-5:00

EROS Data Reference File

Public Inquiries Office

U.S. Geological Survey

Room 678, U.S. Court House

Building

West 920 Riverside Avenue

Spokane, Washington 99201

Phone: 509-456-2524

Hours: 9:00-4:30
EROS Data Reference File

Maps and Surveys Branch

Tennessee Valley Authority

20 Honey Building

311 Broad Street

Chattanooga, Tennessee 37401

Phone: 615.755-2133

Hours: 8:00-4:00

\section{LANDSAT (EARTH RESOURCES TECHNOLOGY SATELLITE) DATA}

The first Earth Resources Technology Satellite, ERTS-1 (now renamed LANDSAT-1), was launched July 23, 1972. LANDSAT-2 was launched on January 22, 1975. LANDSAT flies in a circular orbit 570 miles $(920 \mathrm{~km})$ above the Earth's surface and circles the Earth every 103 minutes, or roughly 14 times per day. Each daytime orbital pass is from north to south. From such a vantage point, each LANDSAT can cover the entire globe, except for the poles, with repetitive coverage every 18 days. A unique feature of the satellite, because of the orbit, is that it views the Earth at the same local time, roughly 9:30 a.m. at the Equator, on each pass. The sensors on board the spacecraft transmit images to, NASA receiving / stations in Alaska, California, and Maryland either directly or from data stored on tape recorders. The data are converted from electronic signals to photographic images and computer compatible tapes at NASA's Goddard Space Flight Center (GSFC) in Greenbelt, Maryland. Master reproducible copies are flown to the EROS Data Center in Sioux Falls, South Dakota, where images are placed in the public domain, and where requests for reproductions are filled for the scientific community, industry, and the public at large. Because of the experimental nature of the satellite and the limited capabilities of NASA ground processing equipment at Greenbelt, approximately 30 days are required from the time the signals are first received on the ground to the time that the data are available to the public at the EROS Data Center. 
LANDSAT presently carries three data acquisition systems: (1) a multispectral scanner (four spectral bands), (2) a return beam vidicon (RBV) or television system, and (3) a data collection system (DCS) to relay environmental data from ground-based data collection platforms (DCP's). The multispectral scanner, or MSS, is the primary sensor system and acquires images of 115 miles $(185 \mathrm{~km}$ ) per side in four spectral bands in the visible and near-infrared portions of the electromagnetic spectrum. These four bands are:

Band 4, the green band, 0.5 to 0.6 micrometres, emphasizes movement of sediment laden water and delineates areas of shallow water, such as shoals, reefs, etc.;

Band 5, the red band, 0.6 to 0.7 micrometres, emphasizes cultural features;

Band 6, the near-infrared band, 0.7 to 0.8 micrometres, emphasizes vegetation, the boundary between land and water, and landforms; and

Band 7, the second near-infrared band, 0.8 to 1.1 micrometres, provides the best penetration of atmospheric haze and also emphasizes vegetation, the boundary between land and water, and landforms.

An analysis of the four individual black and white images or the false-color infrared composite images often permits scientists to identify and inventory different environmental phenomena, such as distribution and general type of vegetation, regional geologic structure, and areal extent of surface water. The repetitive ( 9 or 18 days) and seasonal coverage provided by LANDSAT imagery is an important new tool for the interpretation of dynamic phenomena. It should be noted that because of the

LANDSAT (ERTS).

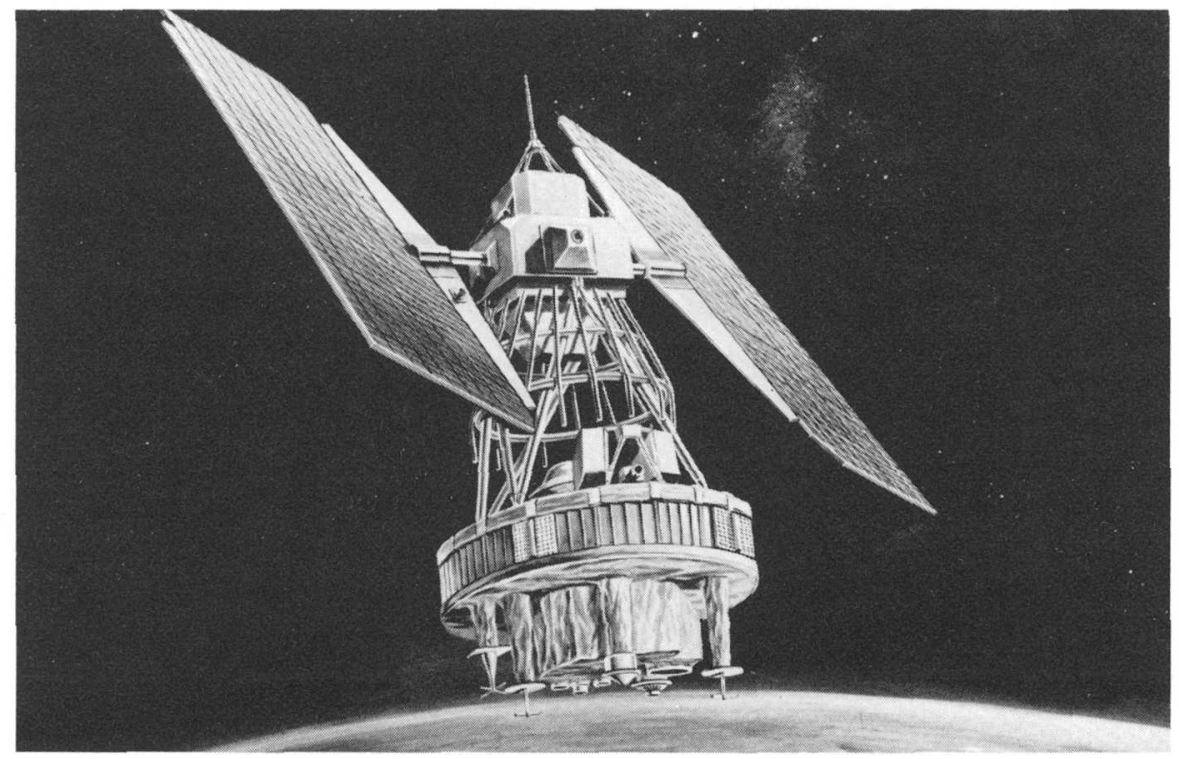


Earth's rotation and the fact that the image is created by an opticalmechanical scanner, ERTS MSS images are parallelograms, not squares. The sides are parallel to the orbital track of the satellite on the Earth's surface. RBV images have a square format because the image is acquired instantaneously.

The arbitrary forward overlap between consecutive LANDSAT images is approximately 10 percent. The sidelap between adjacent orbits ranges from 14 percent at the Equator to 85 percent at the $80^{\circ}$ parallels of latitude.

Latitude and longitude tick marks are depicted at 30-minute intervals outside the image edge. These geographic reference marks are annotated in degrees, minutes, and compass direction. A 15-step gray-scale tablet is exposed on every frame of LANDSAT imagery as it is produced. This scale is used to monitor and control printing and processing func. tions and to provide a reference for analysis related to a particular image. The annotation block directly over the gray scale contains data that give the unique image identification, the geographic location, and the time (with respect to Greenwich mean time) an image was acquired.

If you wish to order a single black and white image, it is best to order band 5 . This band usually gives the best general-purpose view of the Earth's surface. By ordering a complete set of black and white images from all four bands, however, you can see how the same area differs in appearance when filtered to green, red, and near-infrared wavelengths. MSS false-color composites are available as standard products. An MSS false-color composite image is generally created by exposing three of the four black and white bands through different color filters onto color film. On these false-color images, healthy vegetation appears bright red rather than green; clear water appears black; sediment-laden water is powder blue in color; and urban centers often appear blue or blue-gray. MSS false-color composite images which have not already been prepared can be ordered from the Data Center but carry a one-time initial preparation charge of $\$ 50$, not including the cost of any products ordered from the resulting composite.

A set of LANDSAT images has been prepared for the conterminous United States. The 470 scenes required to cover the United States are available in a single black and white band (band 5), all four bands of black and white, or high-quality color composites. The scenes selected were chosen on the basis of quality, optimum time of year (generally spring or summer), and minimum cloud cover.

LANDSAT data in digital form are available as Computer Compatible Tapes (CCT). The tapes are standard $1 / 2$-inch-wide $(12.7-\mathrm{mm})$ magnetic tapes and may be requested in either seven- or nine-track format at 800 or 1,600 bpi. Four CCT's are required for the digital data corresponding to one LANDSAT image. The data for the four bands are interleaved among the four tapes thereby necessitating all tapes to complete a set. The cost of one set (one LANDSAT image) is $\$ 200$. 


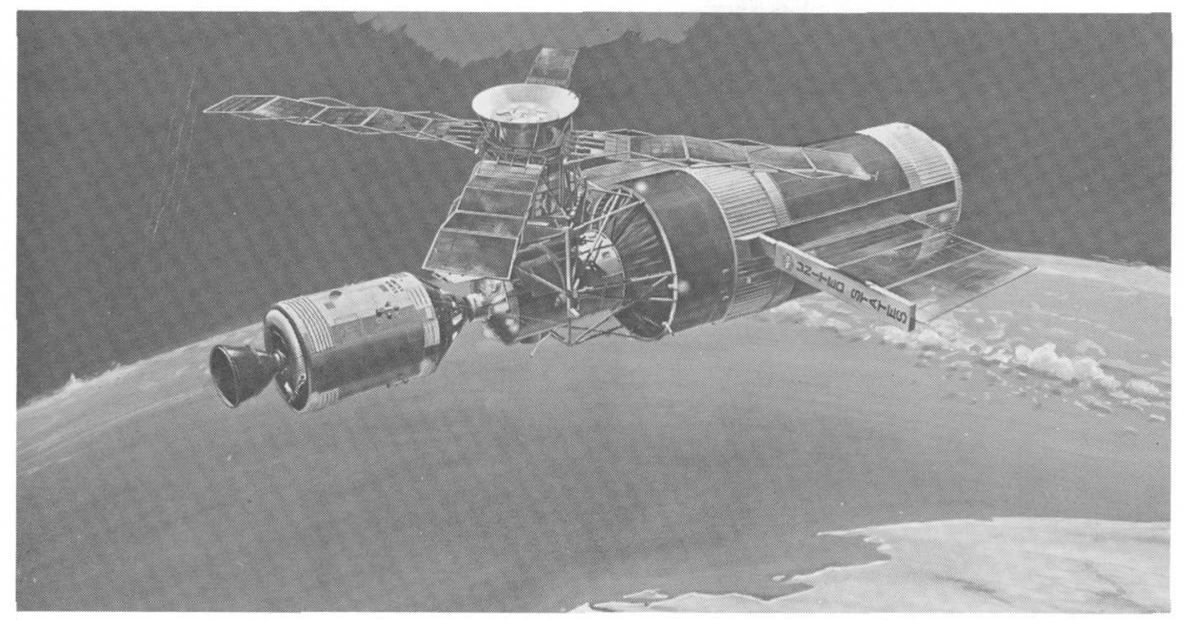

Skylab spacecraft.

\section{SKYLAB DATA}

The NASA Skylab Program consisted of one unmanned and three manned missions. The unmanned space vehicle was placed in orbit in February 1973. The manned missions were Skylab 2, launched on May 22, 1973, and recovered on June 22, 1973; Skylab 3, in orbit from July 28 to September 25, 1973; and Skylab 4, launched on November 16, 1973, and recovered on February 8, 1974.

The spacecraft traveled in an orbit 270 miles $(430 \mathrm{~km})$ above the Earth and acquired photography, imagery, and other data of selected areas between latitudes $50^{\circ} \mathrm{N}$. and $50^{\circ} \mathrm{S}$. The data cover a number of scattered test sites selected to support Earth resources experiments. The photography, however, does not provide complete, cloud-free, and systematic coverage of the Earth's surface between $50^{\circ} \mathrm{N}$. and S. latitudes.

Skylab imagery and photography is available over limited test sites from $50^{\circ} \mathrm{N}$. to $50^{\circ} \mathrm{S}$. latitudes.

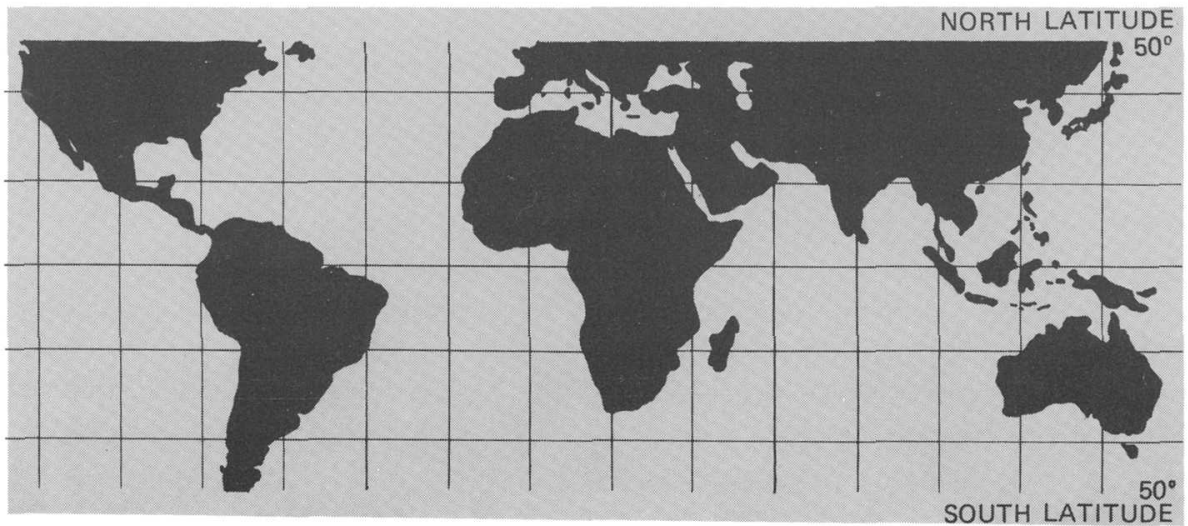


The Skylab Earth Resources Experiment Package (EREP) consisted of six remote-sensing systems and was designed as a spaceborne facility to be used by the scientific community. The systems were:

S190-A-Multispectral Photographic Camera. A six camera array was designed to provide high-quality photography of a wide variety of phenomena on the Earth's surface. Each camera used 70- $\mathrm{mm}$ film and a 6 inch (152-mm) focal length lens. The films used were filtered black and white, color, and false-color infrared. The area covered by each image of this system is 90 by 90 miles (144 by $144 \mathrm{~km}$ ).

S190-B-Earth Terrain Camera. A single, high resolution Earth terrain camera was selected to provide high-resolution photography for scientific study. It used 5-inch (127-mm) film and an 18-inch (457-mm) focal length lens. Various black and white, color, and false-color infrared films were used in the camera. The area covered by each frame of this system was 60 by 60 miles ( 96 by $96 \mathrm{~km}$ ).

S191_-Infrared Spectrometer. Non-imaging.

S192-Multispectral Scanner. Imaging, 13 spectral bands (including one thermal infrared band) between 0.4 and 12.5 micrometres.

S193-Microwave Radiometer/Scatterometer and Altimeter. Non-imaging.

S194-L-Band Radiometer. Non-imaging.

Photographic data from the S190-A and S190-B experiments are available from the Data Center. Data from the other systems are also available from the Data Center but must be individually requested from NASA by the Data Center for duplication and sale in response to an order.

\section{NASA AERIAL PHOTOGRAPHY}

NASA aerial photography is the product of aerial surveys carried out by the NASA Earth Resources Aircraft Program. The program is directed primarily at testing a variety of remote-sensing instruments and techniques in aerial flights generally over certain preselected test sites within the continental United States, but also includes sites in a few foreign areas.

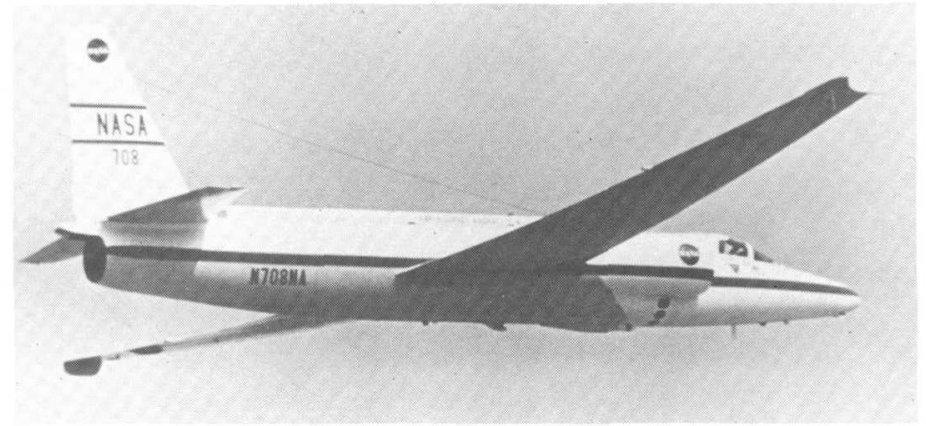

NASA high altitude $\mathrm{U}-2$ aircraft. 
Aerial photography is available in a wide variety of formats from flights at altitudes of a few thousand feet $(1,000 \mathrm{~m})$ up to U-2 and RB$57 \mathrm{~F}$ flights at altitudes above 60,000 feet $(18,000 \mathrm{~m})$. The high-altitude photography is generally available on a 9 . by 9 -inch $(23-$ by $23-\mathrm{cm}$ ) film format at approximate scales of 1:120,000 and 1:60,000. In general, each high-altitude frame of 9 -inch $(23-\mathrm{cm})$ film format photography at $1: 120,000$ scale shows an area approximately 15 miles $(24 \mathrm{~km})$ on a side.

Aerial photography is available in black and white, color, or falsecolor infrared. Since these data are acquired at relatively low altitudes, ground features such as roads, farms, and cities are easily identifiable. Cloud cover is present in some photographs, and NASA aerial photographic coverage is not available for all areas of interest. Some electronic data from the more sophisticated research sensors on the aircraft may also be obtained through the Data Center. These data, however, are of limited areas and long delivery times must be expected.

\section{AERIAL MAPPING PHOTOGRAPHY}

Aerial photography during the past 25 years was acquired by the U.S. Geological Survey and other Federal Government agencies for mapping of the United States. The photography is black and white and has less than 5 percent cloud cover.

Depending on the planned use of the photographs, the aerial-survey altitude ranged from 2,000 feet $(600 \mathrm{~m})$ to 40,000 feet $(12,000 \mathrm{~m})$. The basic film format is 9 by 9 inches $(23$ by $23 \mathrm{~cm}$ ) and shows areas from

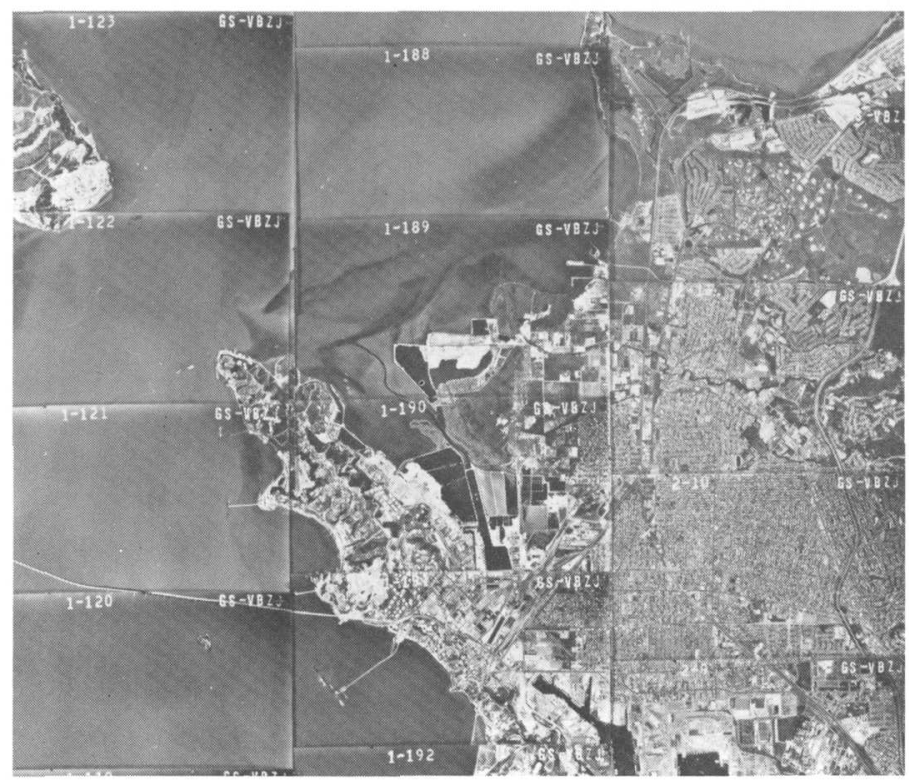

Aerial photographic coverage indexed in mosaic form. 
3 to 9 miles $(4.8$ to $14.4 \mathrm{~km}$ ) on a side depending on the scale of the photograph.

Because of the large number of aerial photographs necessary to show an area on the ground, the photographs have been indexed by mounting a series of consecutive and adjacent overlapping photographs to create a mosaic of photographs of a specified area. These aerial photographic mosaics are referred to as "photo indexes" and allow for rapid identification of photographic coverage of a specific area. Presently, some 43,000 photo indexes are available at the Data Center. To order aerial photography from the Data Center, it is necessary that you initially order a photo index of your area of interest to determine the specific aerial photography needed.

\section{GEMINI-APOLLO PHOTOGRAPHY}

Photographic coverage over limited areas of the Earth acquired by the Gemini and Apollo missions is available from the Data Center. The photographs from the Gemini missions were acquired by handheld, 70 $\mathrm{mm}$ cameras.

\section{GEMINI/APOLLO PHOTOGRAPHIC DATA}

\begin{tabular}{|c|c|c|c|}
\hline MISSION & LAUNCH & RECOVERY & PHOTOGRAPHIC COVERAGE \\
\hline $\begin{array}{l}\text { Gemini III } \\
\text { Gemini IV }\end{array}$ & $\begin{array}{l}\text { March 23, } 1965 \\
\text { June 3, } 1965\end{array}$ & $\begin{array}{l}\text { March 23, } 1965 \\
\text { June 6, } 1965\end{array}$ & $\begin{array}{l}25 \text { color photographs of the Earth. } \\
219 \text { color photographs of the Earth, in- } \\
\text { cluding extensive coverage of the South- } \\
\text { western United States. }\end{array}$ \\
\hline $\begin{array}{l}\text { Gemini V } \\
\text { Gemini VI-A }\end{array}$ & $\begin{array}{l}\text { August } 21,1965 \\
\text { December } 15,1965\end{array}$ & $\begin{array}{l}\text { August 29, } 1965 \\
\text { December } 16,1965\end{array}$ & $\begin{array}{l}250 \text { color photographs of the Earth. } \\
192 \text { black and white and color photographs, } \\
\text { primarily of Africa. }\end{array}$ \\
\hline Gemini VII & December 4, 1965 & December 18,1965 & $\begin{array}{l}429 \text { varied black and white and color } \\
\text { photographs. }\end{array}$ \\
\hline Gemini VIII & March 16, 1966 & March 16, 1966 & $\begin{array}{l}19 \text { black and white and color photographs, } \\
\text { mainly of the Agena launch missile. }\end{array}$ \\
\hline Gemini IX-A & June 3,1966 & June 6,1966 & $\begin{array}{l}362 \text { black and white and color photographs } \\
\text { of the Southwestern United States, } \\
\text { westcentral South America, and Africa. }\end{array}$ \\
\hline Gemini $X$ & July 18,1966 & July 21, 1966 & $\begin{array}{l}371 \text { varied black and white and color } \\
\text { photographs, which include some cover- } \\
\text { age of China, Central America, and the } \\
\text { Straits of Gibraltar. }\end{array}$ \\
\hline Gemini XI & September 12, 1966 & September 15,1966 & $\begin{array}{l}238 \text { black and white and color photographs } \\
\text { of the Earth including the Middle East, } \\
\text { North Africa, and Australia. }\end{array}$ \\
\hline Gemini XII & November 11, 1966 & November 15, 1966 & $\begin{array}{l}403 \text { assorted black and white and color } \\
\text { photographs, covering many areas of the } \\
\text { globe. }\end{array}$ \\
\hline Apollo 6 & April 4, 1968 & unmanned & $\begin{array}{l}370 \text { varied Earth-looking color photographs } \\
\text { taken by a stationary camera. }\end{array}$ \\
\hline Apollo 9 & March 3, 1969 & March 13, & $\begin{array}{l}912 \text { varied Earth-looking color photographs } \\
\text { of selected test areas. }\end{array}$ \\
\hline
\end{tabular}


A special photographic experiment, designated S-065 was conducted on Apollo 9 in March 1969. This experiment used four $70-\mathrm{mm}$ cameras to acquire three types of filtered black and white and one type of false-color infrared photographs. The S-065 photography is available from the Data Center; each picture shows an area approximately 100 by 100 miles (160 by $160 \mathrm{~km})$.

\section{THE GEOGRAPHIC SEARCH AND INQUIRY SYSTEM}

Requests for information about imagery of a specific area will initiate a computerized geographic search. The search can be initiated by mail, visit, or phone, to either the EROS Data Center or one of the EROS Applications Assistance Facilities. You may request a geographic search using any of the three following options:

1. Point search-all images or photographs with any portion falling within 50 miles $(80 \mathrm{~km})$ of the point will be included.

2. Area rectangle - any area of interest defined by four corner coordinates of latitudes and longitudes. All images or photographs with any coverage of the area will be listed. The area must not exceed 200 onedegree squares (for example, $10^{\circ}$ latitude by $20^{\circ}$ longitude).

3. You may enclose a map with a point or area indicated.

When requesting a geographic search from the Data Center be sure to provide all relevant information. This should include acceptable dates and seasons, type of imagery preferred, color, false-color infrared, or black and white, cloud cover, and quality. Cloud cover is given only in percentage, hence no assurance can be given as to where clouds will appear on the resulting photographs or images. A description of your intended application and the use of the data will assist the researcher at the Data Center who initiates the search, thereby resulting in a more concise response to your inquiry.

GEOGRAPHIC AREAS MUST BE CLEARLY IDENTIFIED AND SHOULD BE LIMITED IN SIZE AS MUCH AS POSSIBLE TO AVOID A POTENTIALLY LONG COMPUTER LISTING AND THE NEED TO REVIEW LARGE NUMBERS OF CHOICES. LATITUDE AND LONGITUDE COORDINATE SPECIFICATION IS PREFERRED, SINCE THIS IS THE METHOD REQUIRED FOR THE COMPUTER GEOGRAPHIC SEARCH.

Specification in degrees and minutes normally provides sufficient location accuracy. (Each degree of latitude or longitude is divided into 60 minutes, and each minute into 60 seconds. One minute of latitude is roughly 1 mile.) Coordinates can be found for your area of interest from 


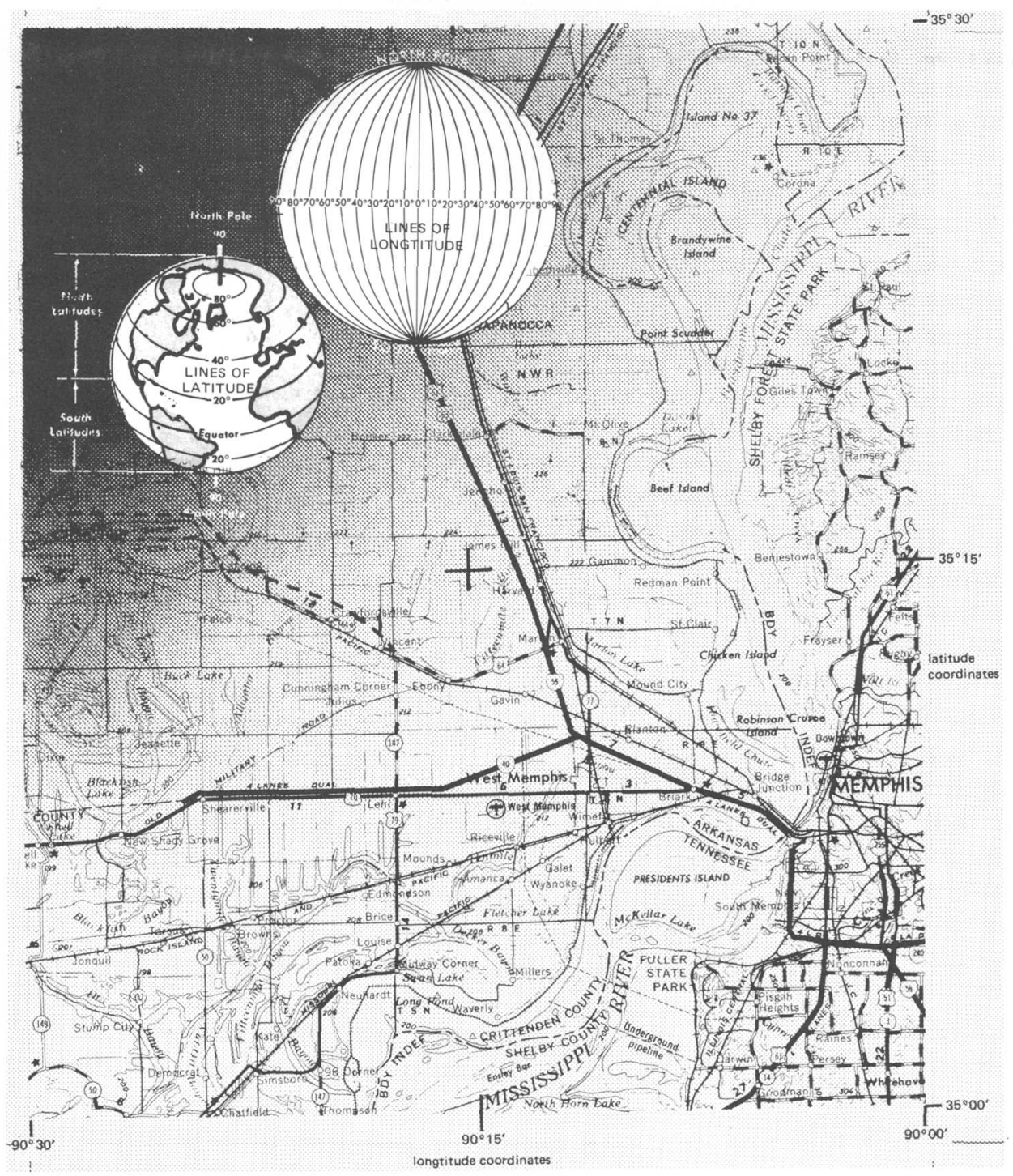

The use of geographic coordinates from an available source will aid in initiating an inquiry for information.

maps in a home library, atlas, or on many State road maps. The alternate method is to enclose a map with your area specifically outlined.

With your inquiry, you will be assigned a contact number used for order processing and control. This number should be retained and used in all future correspondence concerning that inquiry.

The computerized geographic search is made free of charge. Please allow at least 2 weeks for the search to be completed and for the computer listing to be sent to you for image or photograph selection. 


\section{UNDERSTANDING THE COMPUTER LISTING}

The computer listing will contain all images and photographs available over or close to your area of interest. Two printed lines on the computer listing describe in detail the characteristics of each image or photograph. A number of entries may be listed, depending upon the size of the area selected and the restrictions of the supplemental data. Imagery or photography may be available from more than one sourceLANDSAT, Skylab, NASA aircraft, or Survey aircraft-all of which differ significantly in sensor or camera characteristics. Thus, each entry on the computer listing should be carefully studied to determine the best selection for your interest and application. The first line of each entry on the computer listing gives data characteristics, along with information required for subsequent ordering. Specific items to be considered are:

Type Cover-Indicates type of coverage from one of the four sources of

photographs or images available from the Data Center. This must be used to determine the correct order form and ordering procedure.

As a result of an inquiry, the requestor will receive a computer listing of available imagery and photography and a decoding template for interpretation of the printed information.

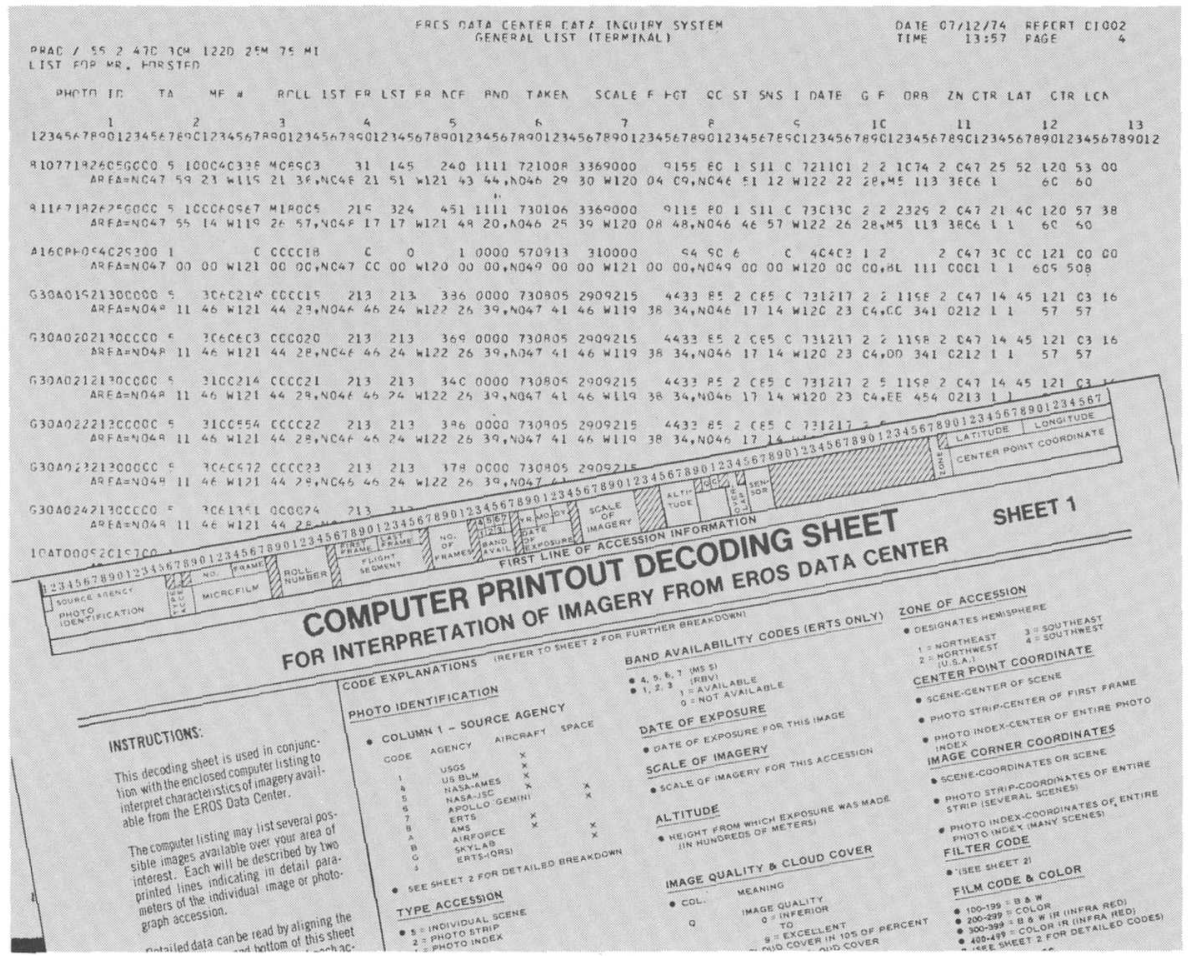


Scene Identification-Indicates a 15-character unique order number to be transferred to the order form when placing an order.

Film Source-Indicates black and white, color, false-color infrared, or black and white infrared film.

Quality_-Indicates the quality of master film roll on the following scale: $0-2$, very poor; $2-4$, poor; $5-6$, fair; and $7-9$, good to excellent.

Cloud Cover-Indicates the approximate cloud cover in percentage, that is $10,40,80$ percent, and so on.

Date Acquired-Gives the date the exposure was made. Read as year, month, day; for example, 740318 indicates March 18, 1974.

Center Point-Gives the latitude and longitude coordinates of the center point of the scene in degrees, minutes, and seconds.

Band Availability - " 1 " indicates availability of a specific spectral band; " 0 " indicates nonavailability.

For all aircraft photographic accessions these items are also noted:

Type Accession-Indicates whether the computer is describing a scene (single photograph), strip (a series of photographs in a strip), or a photo index (mosaic of overlapping photographs). The pertinent codes are " 5 " for an individual photograph, " 2 " for a photo strip accession, and " 1 " for a photo index.

First Frame-Last Frame-Indicates, for all strip accessions, the first and last frames on the master film roll. If the same number is listed, a single photograph is described.

Number of Frames-Lists, for your convenience, the number of frames in the film roll between the first and last frames.

The remaining information on the first line of the computer listing is included primarily for technical use or internal use by the Data Center. The second line of each entry contains the corner coordinates in latitude and longitude which may be plotted to determine the exact ground coverage of either individual frames, strips, or photo indexes.

The image size of the master reproducible is shown (in millimetres) at the end of the second line and may be needed to order some types of aircraft data. A template is provided for decoding the computer listing. When a choice of the most suitable data has been made, place an order using the appropriate order form.

LANDSAT and Skylab imagery and photography are indexed and listed by individual frame. Thus each entry on the computer listing describes a single image or photograph which can be ordered directly by the unique identification number.

NASA Aerial Photography is indexed by individual photograph or by strip which describes two or more successive forward overlapping photographs along an aircraft flight line. Each entry on the computer listing describes a single photograph or adjoining scenes which are successive photograph frames on the master film roll. 


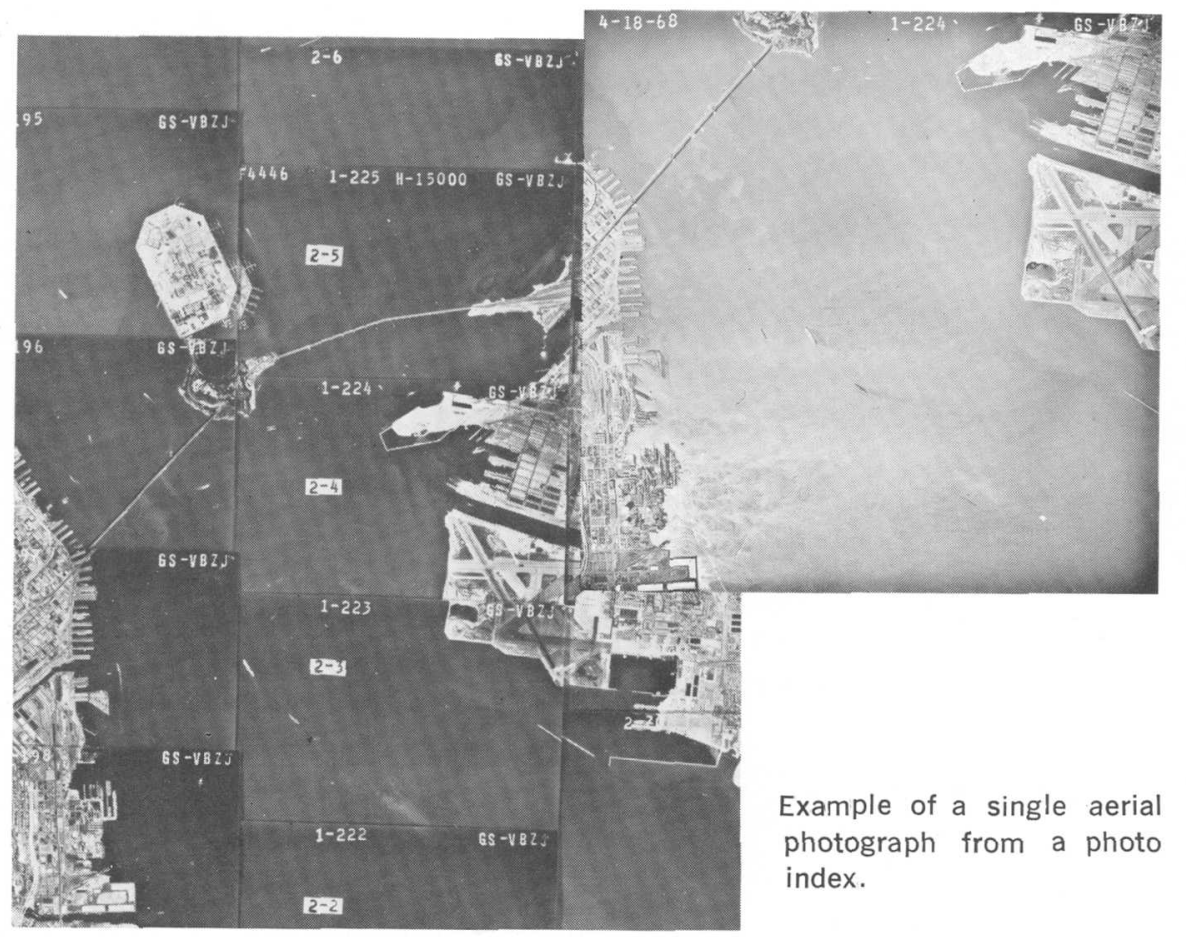

When more than one scene is described, it is necessary to plot and interpolate along the strip to determine the exact photograph to order. More explicit instructions can be found in the Placing An Order section.

U.S. Geological Survey and other Aerial Mapping Photography is listed on photo indexes, which contain many overlapping photos and from which individual photographs can be ordered.

Photo indexes can be ordered directly by supplying geographic coordinates or by ordering from a computer listing of a geographic search.

Individual aerial photographs are not geographically accessible. Therefore, they will not appear on the computer search listing and can only be ordered from a photo index or if the individual photo number is already known.

\section{PLACING AN ORDER}

Orders for reproductions of data from the EROS Data Center are accepted from individuals, governmental organizations, universities, and industries in the United States and foreign countries. Orders can be placed by personal visit, telephone, or mail to the Data Center. Orders can also be placed at any of the EROS Applications Assistance Facilities:

All orders must be accompanied by check, money order, purchase order, or authorized account identification; processing cannot be initiated 
until valid and accurate payment is received. Your check or money order should be made payable to the U.S. Geological Survey. Standing (open) accounts may be established by repetitive users. To open a standing account, a check must be remitted for the amount to be deposited. You will be informed of the account number, and future orders can be placed using this open account number. You may add to the balance or obtain a refund of the unused portion at any time. A $\$ 100$ minimum is required to establish a standing account.

Quality of the reproduction cannot exceed that of the master film available at the Data Center. Every product leaving the Data Center undergoes a rigid inspection to insure that internal quality standards are met. Occasionally, you may find that a product has certain defects, such as small scratches, pinholes, or stains, or that the color balance or density of the reproduction is not exactly as you expected it should be. In these cases, you may be assured that it has been inspected against the quality of the original reproducible and that everything has been done to produce as good a product as possible. As with any large production facility, however, substandard products sometimes do reach the user. Such products should be returned to the Data Center for reprocessing or a refund. Our policy is to provide high quality products to all users, and to make certain that data users are satisfied with all products.

All shipments are prepaid, and no postage charges are made. With each outgoing order, a prepaid postage card is included soliciting your comments by return mail. We solicit your suggestions and criticisms as a positive method for improving service and quality.

Precision photographic processing is performed in a dust-

free environment for all photographic reproductions.

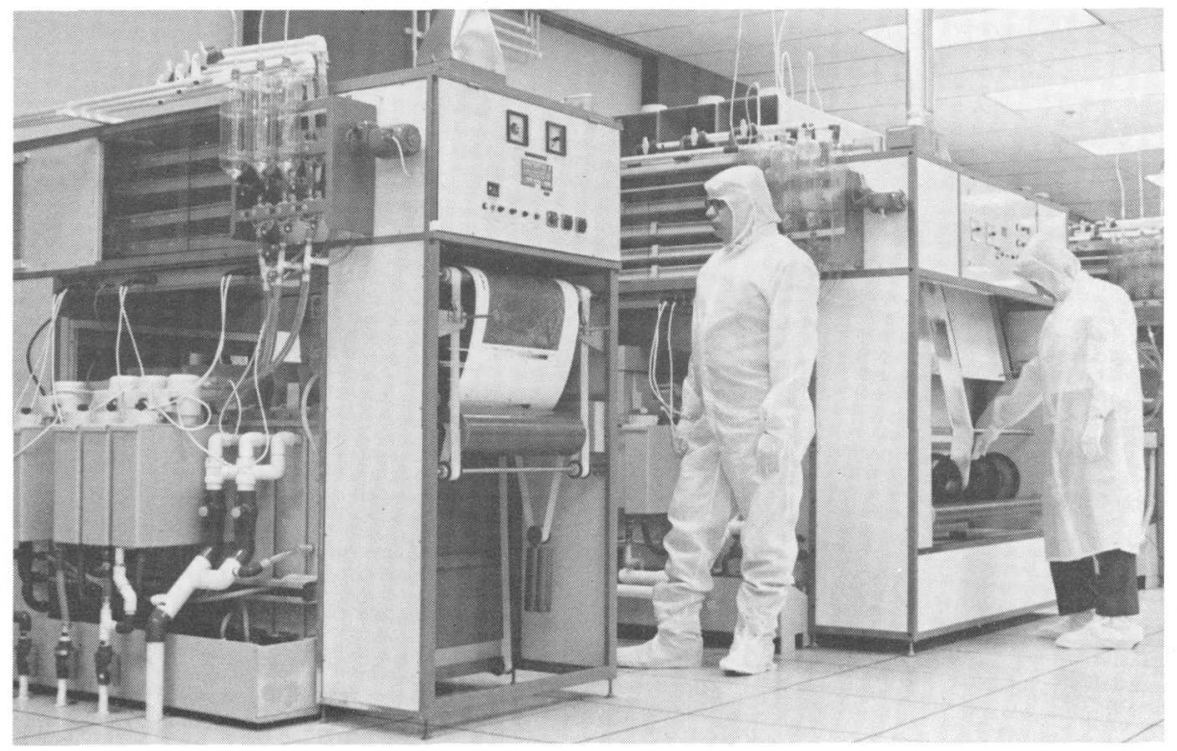


Should you have difficulty in placing an inquiry or order, need assistance in selection of data, or have questions regarding your order or additional services, you may write or call:

\section{Customer Relations Unit \\ EROS Data Center \\ Sioux Falls, South Dakota 57198 \\ Phone: 605-594.6511, extension 151 \\ FTS: $\quad 605-594-6151$}

Please allow a minimum of 2 to 3 weeks for delivery of all orders. A longer time may be required for the production of computer compatible tapes or the completion of very large or complex orders.

Information on the order forms for each type of data is given below:

\section{LANDSAT (EARTH RESOURCES TECHNOLOGY SATELLITE) DATA}

LANDSAT data should be ordered with the LANDSAT (ERTS) order form. LANDSAT images are indexed by a unique scene number. If you are ordering from a computer listing, transfer the scene identification number of the selected image from the computer list to the LANDSAT (ERTS) order blank, and complete the order form as indicated on the reverse side. If ordering from other references, please be sure that the scene identification number is included on the order form.

If you are interested only in obtaining a LANDSAT (ERTS) image of an area within the 48 conterminous States of the United States, we suggest that you use the LANDSAT (ERTS) SINGLE COVERAGE order form. Instructions are on the reverse, and the accompanying map identifies, by a unique number, the nominal center points of each satellite image.

\section{SKYLAB DATA}

Skylab photography or imagery should be ordered with the Skylab order form. Each photograph is indexed by scene number; each entry and scene identification number on the computer listing describe a single photograph.

\section{NASA AERIAL PHOTOGRAPHY}

NASA aerial photography should be ordered with the NASA Aircraft (Aerial) Photography order form. A careful study should be made of the geographic search computer listing. In most cases, NASA aerial photography is accessed by strip. The number of scenes described by the strip can be determined from the first and last frame numbers and the number of frames on the computer listing. The center coordinates on the 
computer listing are given for the first frame of the flight line. The four corner geographic coordinates for the entire strip are shown on the second line of the computer listing. In some cases, only one frame is described, in which case interpolation of frames is not required.

When more than one frame is described, it will be necessary to plot the four corner geographic coordinates of the strip on a map. This will show complete coverage of the strip and assist you in the interpolation and selection of the frame(s) covering your area of interest. To do this, the strip must be equally divided into the number of frames identified on the computer listing and those divisions or frames must be assigned a frame number. This will result in a graphic presentation of the strip coverage which will allow you to identify and select the desired frame(s). To insure that you receive the right coverage, it is recommended that you also consider ordering the adjoining frames.

When you have determined which photograph or strip from the computer listing covers your area of interest, an order can be placed by one of the following options:

1. When only one frame is described on the computer listing, transfer the scene identification and frame numbers directly on to the order form.

2. When interpolating an exact frame or frames within a strip, transfer the scene identification number directly and record the first and

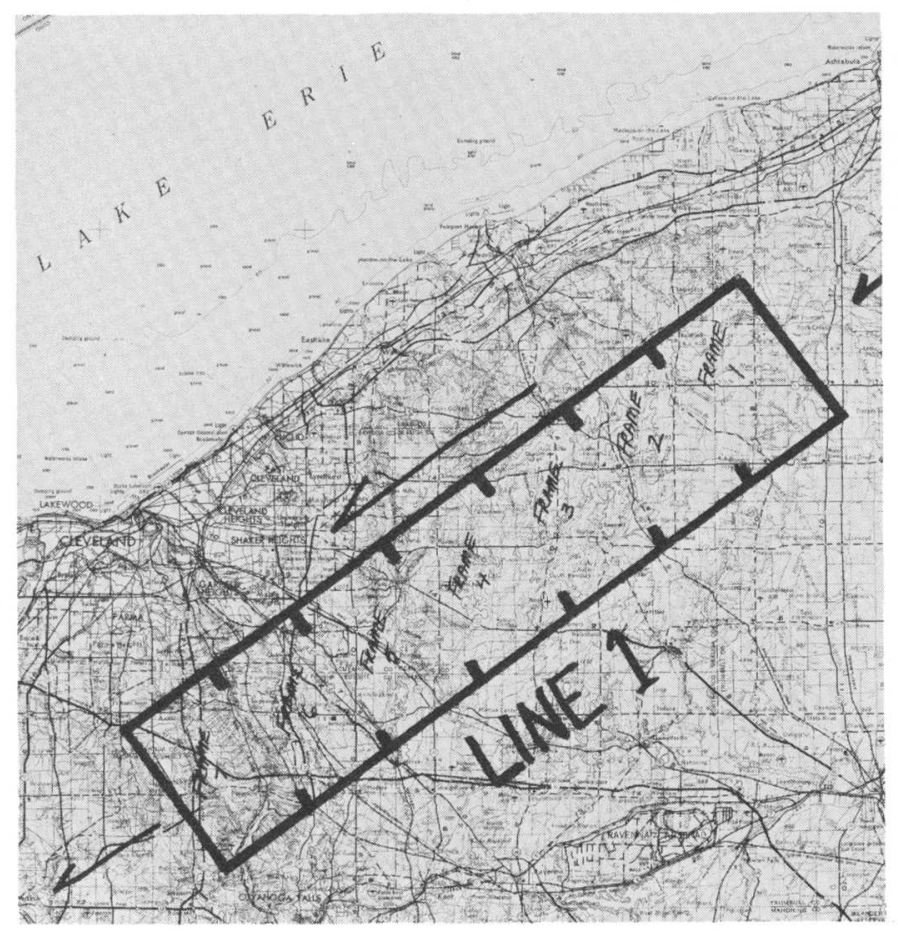

NASA aerial photography is listed by film strip in the computer listing. 
last frame numbers of the part of the strip you want on the order form.

3. To order the entire series of photos on the strip, transfer the scene identification number and first and last frame numbers directly from the computer listing on to the order form.

Refer to the detailed instructions on the reverse side before completing the order form.

\section{AERIAL MAPPING PHOTOGRAPHY}

Photo indexes provide access to U.S. Geological Survey and other aerial photography. If you do not have previous knowledge of the photo or frame number, the index must first be ordered so that the appropriate frame number can be found. From the photo index, the project, roll, and frame number can be located and transcribed to the Aerial Mapping Photography order form. Thus, two steps may be required in ordering:

1. Order the photo index for the geographic area of interest, and

2. From the photo index, select and order the individual frames of interest.

Photo indexes can be ordered by using the Aerial Mapping Photography order form or by supplying the geographic location. Indexes also appear on and can be ordered from a computer listing. Individual aerial photographs are not indexed geographically and will not appear on the computer listing. To order a photo index, identify the exact latitude and longitude of the corner coordinates or provide a map with the area outlined. Once you have received the photo index and identified your area of interest put the project, roll, and frame number(s) on to the Aerial Mapping Photography order form.

Aerial photography is usually forward overlapped at least 60 percent and sidelapped at least 30 percent for stereo viewing. (Forward overlap is defined as the area of coverage common to successive photographs along a flight line; sidelap is the area of coverage common to photographs from adjacent flight lines.) Alternate photographs can be ordered within a flight line to provide complete ground coverage. All photo indexes are priced at $\$ 3$ and are available in 1 or 2 sizes: 10 by 12 inches $(25.4$ by $30.5 \mathrm{~cm}$ ) or 20 by 24 inches $(51$ by $61 \mathrm{~cm}$ ), depending on the scale and area covered by the photo index. Nine- by nine-inch (23. by $23-\mathrm{cm}$ ) paper and film products are automatically dodged when printed. Users desiring undodged products should so state when ordering. (Note: Dodging is a means of controlling the negative's overall exposure to light during the process of printing. By doing this, areas normally dark may be lightened and vice versa to show more detail.) U.S. Geological Survey aerial photography is available only in black and white and has less than 5 percent cloud cover. 


\section{PLACING A STANDING ORDER FOR LANDSAT (ERTS) DATA}

Two basic options are available for placing standing orders for either data or information from the EROS Data Center:

1. You may specify an area for which any new LANDSAT imagery will be automatically printed and shipped to you, or

2. You may specify an area for which the Data Center will notify you of any new imagery and the order can subsequently be placed by you.

Should you decide to place a standing order for new data (option 1), you must agree to accept all data for your geographic area if it meets your specifications for cloud cover, quality, and type of remotely sensed data. Any image having any part within the geographic location defined by you will be shipped. You must also establish prepayment with the EROS Data Center by placing money on deposit in a standing account or by issuing a blanket purchase order or valid account number against which you will be billed monthly. If you select option 2, the minimum requirement is that some data be ordered once every 120 days; otherwise the standing order for this information will automatically be cancelled.

\section{CUSTOM PROCESSING}

Custom processing to unique scale and image format is also available from the Data Center. These products normally require longer periods of time for completion. Pricing is based on three times the standard price, or for intermediate enlargements, three times that of the next larger size standard product.

When custom processing is required, indicate CUSTOM under RE. MARKS on the order form and remit triple the standard price.

\section{PRIORITY SERVICES}

A priority system for rapid delivery of products is available whereby orders will be shipped within 5 working days of receipt. For providing this service, three times the standard price is charged. Priority processing will only be accepted when imagery is specifically identified and standard products are ordered.

If for any reason shipment is not made within the 5 days, the cost for each product reverts to standard price and a refund or credit is made.

To receive this service, indicate PRIORITY under REMARKS on the order form and remit triple the standard price. 


\section{FOREIGN ORDERS}

Copies of all remotely sensed data held in the archives at the EROS Data Center are available to individuals from all countries.

In preparing payment, it is suggested that you ask a local bank to make the necessary currency rate adjustment. Your check or money order should be made out in U.S. dollars and cents, and payment should accompany your order. Most banks charge a nominal processing or exchange fee; therefore, please make sure that this fee will not be deducted from the check to be submitted for payment. Each check must be made out in the amount of the total cost of your order. If your check is sent to us directly from your bank, please inform the bank that your contact number must appear on the check and accompanying correspondence.

\section{PHOTO CREDIT}

There are no restrictions on the reprinting of images. It is requested, however, that the National Aeronautics and Space Administration (NASA) be given credit for the original LANDSAT (ERTS), Skylab, Apollo, or Gemini imagery or photographs and NASA aerial photography; that the U.S. Geological Survey be given credit for USGS aerial photography; and that the Survey receive credit for the reproduction. We also ask that the unique scene identification number be published with each image or photograph to aid those who may wish to order a copy.

\section{OTHER PRODUCTS}

A large variety of other accession aids, imagery, and electronic data are available through the EROS Data Center. These include standard LANDSAT (ERTS) catalogs as prepared by NASA in two series: The U.S. STANDARD CATALOG (all data of the U.S., and parts of Canada and Mexico), and the NON.U.S. STANDARD CATALOG (all other foreign areas). Cumulative catalogs have been published to cover data available from launch of LANDSAT-1 through July 23, 1974 for the U.S. STANDARD CATALOG and from launch of LANDSAT-1 through July 23, 1973 for the NON.U.S. STANDARD CATALOG. Four volumes comprise each of these cumulative catalogs. After the cumulative issues, the catalogs have been issued monthly and show data processed during the month rather than data acquired during the month. They contain information on areal coverage of data included, availability of computer compatible tapes, and, in the U.S. STANDARD CATALOG, a graphic presentation of percentage of cloud cover. Copies of these catalogs may be purchased from the Data Center at a cost of $\$ 1.25$ per volume. 


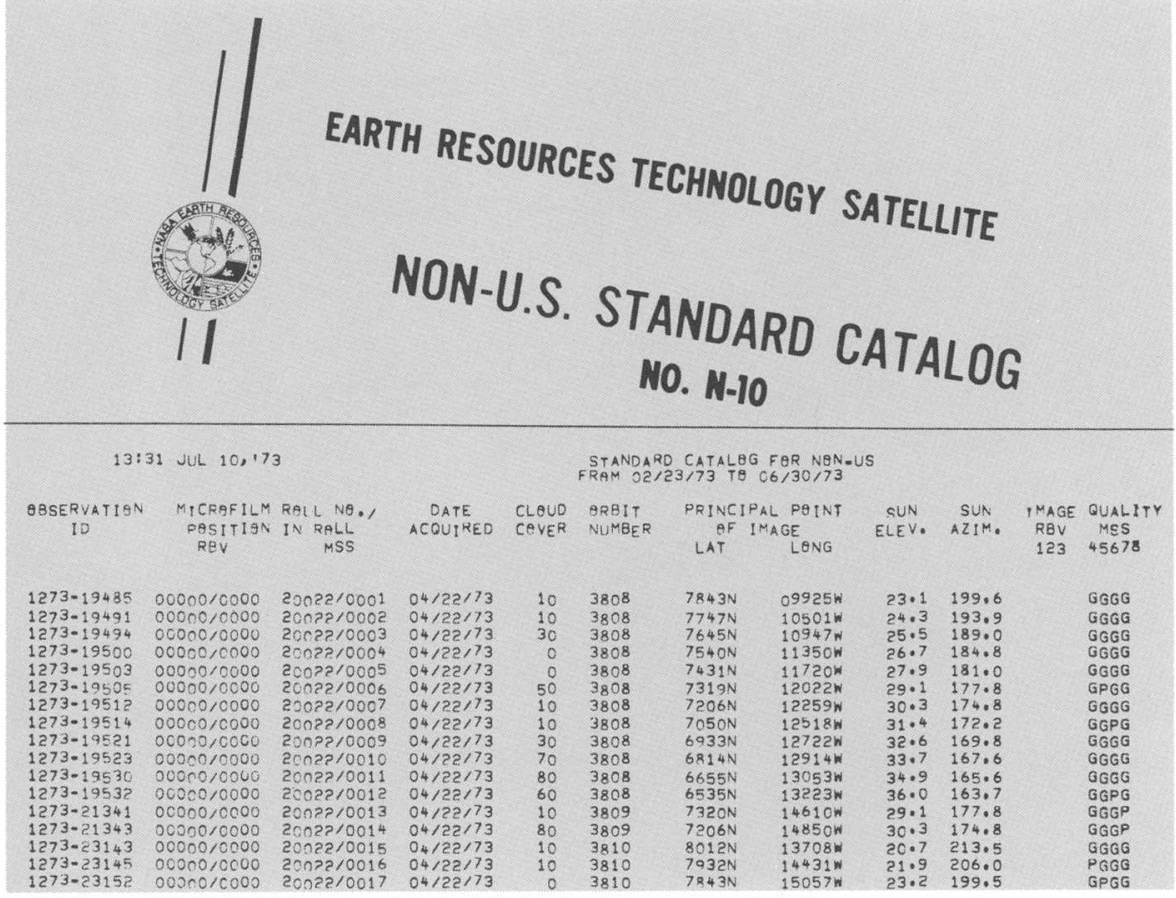

Some LANDSAT (ERTS) data have been processed to precise geometric accuracies (scene corrected or precision processed). Data from the RBV sensor from LANDSAT-1 and LANDSAT-2 are also available. Copies of $16-\mathrm{mm}$ microfilm used to review most types of imagery are available for purchase from the Data Center.

The Soil Conservation Service of the U.S. Department of Agriculture has compiled from LANDSAT (ERTS) imagery black and white mosaics of the conterminous United States and Alaska. They are not available from the Data Center. Orders or requests for further information should be addressed to the:

\section{Cartographic Division}

Soil Conservation Service

Federal Center, Building No. 1

Hyattsville, Maryland 20782

A lithographic copy of the mosaic of the conterminous United States, band 5 or band 7 , at a scale of $1: 5,000,000$ is available for $\$ 1.25$ from:

U.S. Geological Survey

Branch of Distribution 1200 South Eads Street Arlington, Virginia 22202 


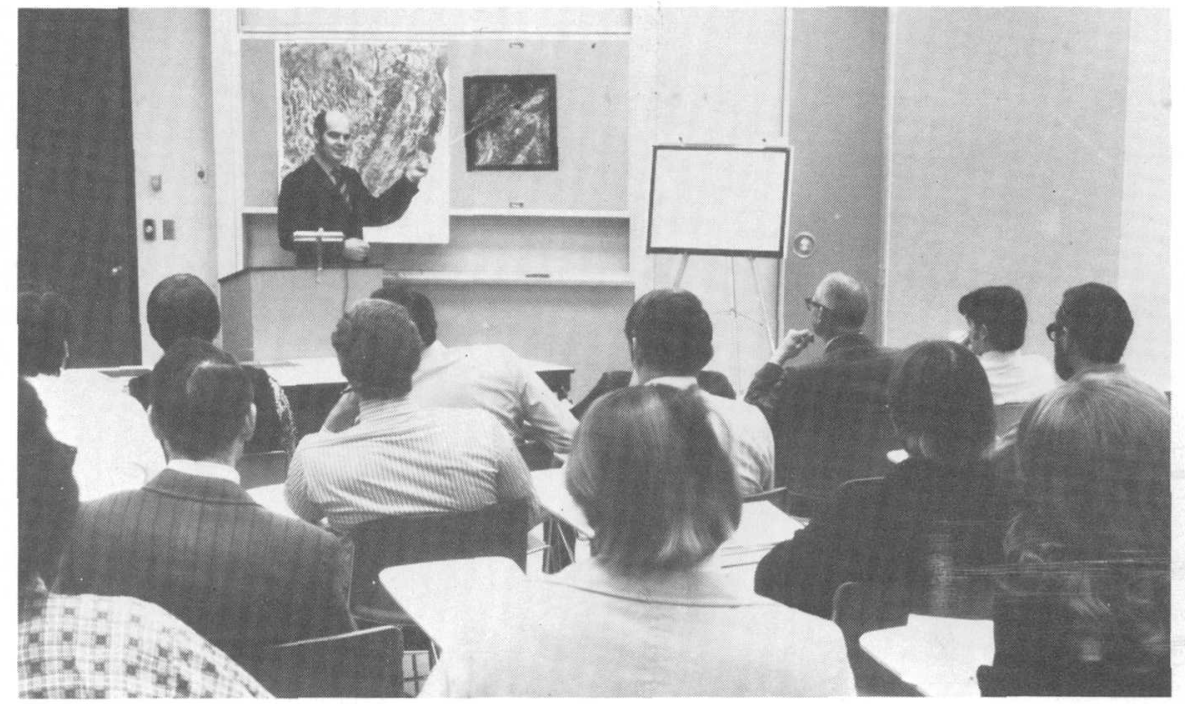

Training courses in remote sensing are conducted at frequent intervals.

\section{APPLICATIONS ASSISTANCE}

Training in remote sensing and assistance in techniques for analysis of remotely sensed data are available at the EROS Data Center. Inquiries can be made by telephone, letter, or personal visit. The Applications Assistance Branch of the Data Center should be contacted before making travel plans.

Periodically, training programs in remote sensing are given at the EROS Data Center. Normally these programs are up to 1 week in length and stress the use of data in a particular application, such as agricultural inventory or water management. Approximately twice a year, a 3week course is offered for foreign nationals that stresses the fundamentals of remote sensing and introduces the application of remotely sensed data to different resource problems. The formal training is supplemented by a series of slide and magnetic tape packages that cover the basic methodology of remote sensing and selected applications.

The EROS Data Center has a developing capability to perform computer-assisted analysis of imagery. Special devices permit the experimental use of digital analysis techniques to classify phenomena by their reflectance or emittance in different parts of the electromagnetic spectrum.

The Applications Assistance Branch also maintains a technical library of information on remote sensing of Earth resources for the use of students who are attending training courses, visitors, and Data Center personnel. 
REMOTE

TERMINAL

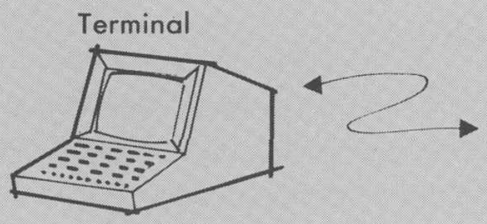

BATCH MODE

CLASSIFICATION \&

FEATURE EXTRACTION
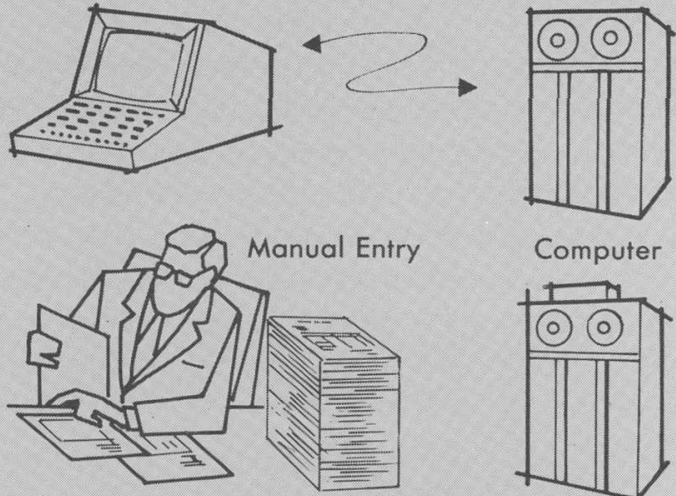

Computer

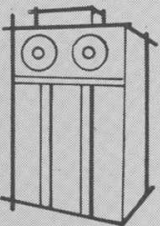

INTERACTIVE

HARDWIRED

FEATURE

EXTRACTION

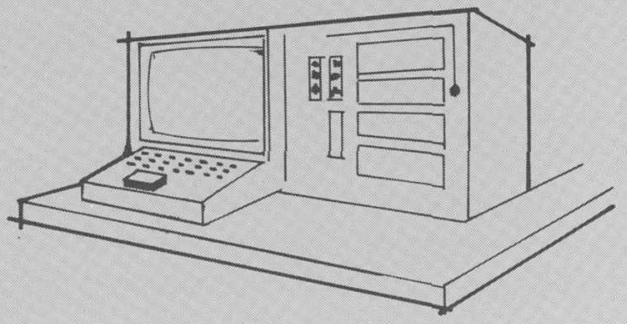

Interpretation of imagery is accomplished through analytical equipment at the Data Center.

Fellowships, visiting scientist appointments, and the use of advanced analytical equipment are available, but acceptance and scheduling of these arrangements are on a case-by-case basis.

All inquiries about applications assistance, fellowships, or the use of analytical equipment at the Data Center should be addressed to:

Applications Assistance Branch

EROS Data Center

Sioux Falls, South Dakota 57198

Phone: 605-594-6511, extension 111

FTS: $\quad 605-594-6111$

\section{VISITS, TOURS, AND NEWS MEDIA INQUIRIES}

The visitors' lobby of the EROS Data Center is open to the general public from 8 a.m. to $4: 30$ p.m. on weekdays and from 10 a.m. to 4:30 p.m. on Saturdays. Pictorial exhibits and photographic gallery displays 


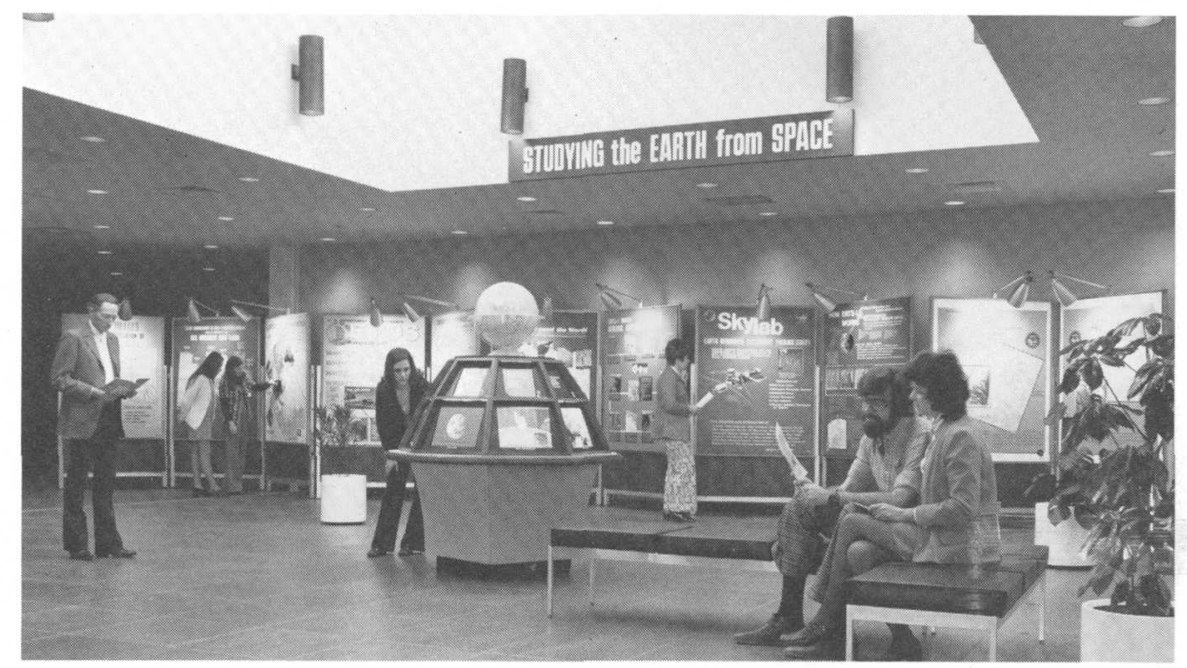

The visitors' lobby contains various displays of Data Center activities.

are located in the lobby area. Guided tours and film presentations for individuals and small groups are offered on weekdays at 10:30 a.m. and 2:30 p.m. Guided tours and educational slide and film presentations for upper elementary school, high school, college groups, and for service clubs and professional organizations, as well as for the news media, may be arranged by contacting:

Community Affairs Representative

EROS Data Center

Sioux Falls, South Dakota 57198

Phone: 605-594-6511, extension 546.

FTS: $\quad 605-594-6546$

\section{THE EROS DATA CENTER IN THE FUTURE}

The EROS Data Center will continue to provide archival storage, processing, and dissemination of Earth resources information with emphasis on rapidly providing more data of higher quality and information content. New state-of-the-art digital data processing and handling systems will be installed as they become available, allowing imagery to be produced in a geometrically correct mode with tonal density of images and formats customized to the specific requirements of the user.

The EROS Data Center also functions as an integral part of the National Cartographic Information Center (NCIC) system for photographic products. 


\section{OTHER SOURCES OF INFORMATION}

Quarterly Literature Review of the Remote Sensing of Natural Resources. University of New Mexico, Albuquerque, New Mexico 87131. This publication lists the majority of published materials in remote sensing from NASA, National Technical Information Service (NTIS), Engineering Index, and four other data bases. It is subdivided into six categories covering all areas of remote-sensing applications and research. U.S. subscription is $\$ 50$ a year.

Various Symposia on Experimental Results Obtained from the Earth Resources Technology Satellite (LANDSAT).

National Aeronautics and Space Administration. Code ER, Washington, D.C. 20546. These are available from the National Technical Information Service, 5285 Port Royal Road, Springfield, Virginia 22151.

NASA Earth Resources Survey Program Weekly Abstracts.

NTIS (address above). Published weekly, these abstracts list significant results and other LANDSAT reports. Annual subscription price is $\$ 30$.

Proceedings of the Nine International Symposia on Remote Sensing of Environment.

Environmental Research Institute of Michigan (ERIM), University of Michigan Extension Service, Ann Arbor, Michigan 46107. Copies of proceedings volumes for the nine symposia may be purchased directly from ERIM. Prices vary.

\section{Photogrammetric Engineering and Remote Sensing.}

American Society of Photogrammetry, 105 North Virginia Avenue, Falls Church, Virginia 22046. A monthly journal available in most college libraries. $\$ 15$ a year.

Data Users Handbook.

General Electric Company, Space Division, Attn: Bruce Rogers, 5030 Herzel Place, Beltsville, Maryland 20705. A comprehensive handbook designed to satisfy serious users' needs for pertinent and sufficient information about the LANDSAT Program, LANDSAT data products and other materials and services available. Appendixes provide thorough treatment of selected topics considered to be of special interest to many users. $\$ 10$.

Remote Sensing with Special Reference to Agriculture and Forestry. National Academy of Sciences, 2101 Constitution Avenue NW., Washington, D.C. $20037 . \$ 12.95$.

\section{Studying the Earth from Space.}

Superintendent of Documents, U.S. Government Printing Office, Washington, D.C. 20402. Illustrated booklet on remote sensing of the Earth's resources. 65 cents. 
As the Nation's principal conservation agency, the Department of the Interior has responsibility for most of our nationally owned public lands and natural resources. This includes fostering the wisest use of our land and water resources, protecting our fish and wildlife, preserving the environmental and cultural values of our national parks and historical places, and providing for the enjoyment of life through outdoor recreation. The Department assesses our energy and mineral resources and works to assure that their development is in the best interests of all our people. The Department also has a major responsibility for American Indian reservation communities and for people who live in Island Territories under U.S. administration.

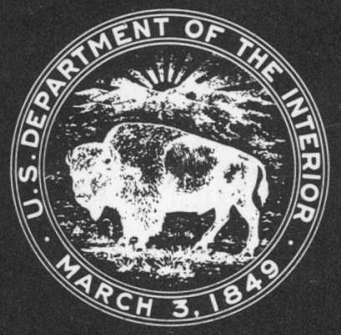

